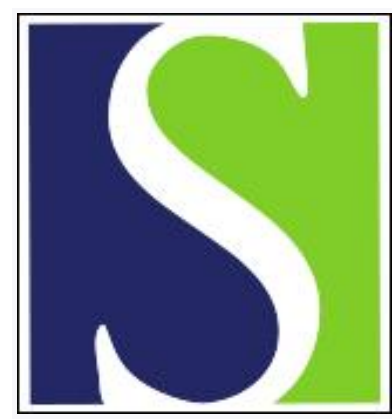

Scand J Work Environ Health 2001;27(4):219-226

https://doi.org/10.5271/sjweh.608

Issue date: Aug 2001

Health effects of occupational exposure to acrylamide using hemoglobin adducts as biomarkers of internal dose

by Hagmar L, Törnqvist M, Nordander C, Rosén I, Bruze M, Kautiainen A, Magnusson A-L, Malmberg B, Aprea P, Granath F, Axmon A

Affiliation: Department of Occupational and Environmental Medicine, University Hospital, SE-221 85 Lund, Sweden. lars.hagmar@ymed.lu.se

The following articles refer to this text: 2001;27(4):217-218; 2004;30(1):21-29; 2006;32(2):154-159; 2011;37(2):136-146

Key terms: acrylamide; allergic contact dermatitis; biomarker; dose-response association; grouting agent; health effect; hemoglobin adduct; internal dose; irritative symptom; N-methylolacrylamide; occupational exposure; peripheral nervous symptom; tunnel worker

This article in PubMed: www.ncbi.nlm.nih.gov/pubmed/11560335 


\title{
Health effects of occupational exposure to acrylamide using hemoglobin adducts as biomarkers of internal dose
}

\author{
by Lars Hagmar, MD,1 Margareta Törnqvist, PhD, ${ }^{2}$ Catarina Nordander, MD, ${ }^{1}$ Ingmar Rosén, MD, ${ }^{3}$ \\ Magnus Bruze, MD, ${ }^{4}$ Antti Kautiainen, PhD, ${ }^{2}$ Anna-Lena Magnusson, ${ }^{2}$ Birgitta Malmberg, MD,${ }^{1}$ Pia \\ Aprea, ${ }^{1}$ Fredrik Granath, PhD, ${ }^{5}$ Anna Axmon, LicMedSc ${ }^{1}$
}

\begin{abstract}
Hagmar L, Törnqvist M, Nordander C, Rosén I, Bruze M, Kautiainen A, Magnusson A-L, Malmberg B, Aprea P, Granath F, Axmon A. Health effects of occupational exposure to acrylamide using hemoglobin adducts as biomarkers of internal dose. Scand J Work Environ Health 2001;27(4):219-226.
\end{abstract}

\begin{abstract}
Objectives This study assessed the health effects of occupational acrylamide exposure using hemoglobin (Hb) adducts as biomarkers of internal dose.

Methods Two hundred and ten tunnel workers exposed for about 2 months to a chemical-grouting agent containing acrylamide and $\mathrm{N}$-methylolacrylamide underwent a health examination. Blood samples were drawn for the analysis of $\mathrm{Hb}$ adducts of acrylamide. Fifty workers claiming recently developed or deteriorated symptoms of the peripheral nervous system (PNS) were referred to a neurophysiological examination. Workers with $\mathrm{Hb}$-adduct levels exceeding $0.3 \mathrm{nmol} / \mathrm{g}$ globin attended follow-up examinations 6,12 , and 18 months after exposure cessation.

Results Forty-seven workers had Hb-adduct levels within the normal background range $(0.02-0.07 \mathrm{nmol} / \mathrm{g}$ globin), while the remaining $163 \mathrm{had}$ increased levels up to a maximum of $17.7 \mathrm{nmol} / \mathrm{g}$ globin. Clear-cut doseresponse associations were found between the Hb-adduct levels and PNS symptoms. Thirty-nine percent of those with $\mathrm{Hb}$-adduct levels exceeding $1 \mathrm{nmol} / \mathrm{g}$ globin experienced tingling or numbness in their hands or feet. A no-observed adverse effect level of $0.51 \mathrm{nmol} / \mathrm{g}$ globin was estimated for numbness or tingling in the feet or legs. For 23 workers there was strong evidence of PNS impairment due to occupational exposure to acrylamide. All but two had recovered 18 months after the cessation of exposure.

Conclusions Occupational exposure to a grouting agent containing acrylamide resulted in PNS symptoms and signs. The use of $\mathrm{Hb}$ adducts of acrylamide as a biomarker of internal dose revealed strong dose-response associations. The PNS symptoms were, however, generally mild, and in almost all cases they were reversible.
\end{abstract}

Key terms allergic contact dermatitis, dose-response associations, grouting agent, irritative symptoms, $\mathrm{N}$ methylolacrylamide, peripheral nervous symptoms, tunnel workers.

During the construction of a railway tunnel through Hallandsås, a bedrock ridge in southern Sweden, a chemical grouting agent containing acrylamide and Nmethylolacrylamide was used due to the considerable water leakage. About $1500 \mathrm{t}$ of the grouting agent was injected into the ridge, mainly during August and September of 1997. Presumably because of the high water flow, the polyacrylamide polymerization was incomplete, and high concentrations of acrylamide and $\mathrm{N}$ methylolacrylamide therefore occurred in the leakage water from the tunnel. Part of the leakage water was pumped into a tiny creek. Cows who drank the creek water, containing concentrations of up to $92 \mathrm{mg} / \mathrm{l}$ of acrylamide and $342 \mathrm{mg} / \mathrm{l}$ of $\mathrm{N}$-methylolacrylamide,

1 Department of Occupational and Environmental Medicine, University Hospital, Lund, Sweden.

2 Department of Environmental Chemistry, Wallenberg Laboratory, Stockholm University, Stockholm, Sweden.

3 Department of Clinical Neurophysiology, University Hospital, Malmö, Sweden.

4 Department of Occupational and Environmental Dermatology, University Hospital, Malmö, Sweden.

5 Department of Medical Epidemiology, Karolinska Institutet, Stockholm, Sweden.

Reprint requests to: Dr Lars Hagmar, Department of Occupational and Environmental Medicine, University Hospital, SE-221 85 Lund, Sweden. [E-mail: lars.hagmar@ymed.lu.se] 
developed severe neurological symptoms, and fish in a downstream fish farm died. When this occurrence was discovered on 30 September 1997, the tunnel construction was immediately discontinued. It was, by then, also obvious that some of the tunnel workers could have been heavily exposed to acrylamide and N-methylolacrylamide. Both substances can easily be taken up in the body through intact skin, inhalation, and the gastrointestinal tract (1).

The critical effect of acrylamide is its neurotoxicity, affecting the peripheral nerve system, but at higher doses also the central nervous system (2). Acrylamide is also a skin and airway irritant (3). It is probably carcinogenic to humans (4) and has caused reproductive disruption in experimental animals (5). N-methylolacrylamide is, compared with acrylamide, a considerably weaker neurotoxic and carcinogenic agent (4). The biological half-time of free acrylamide is short in humans (approximately 4.7 hours) (6), and detectable plasma levels are rarely found, even in workers who have experienced high exposure levels. However, hemoglobin $\mathrm{Hb}$ adducts of acrylamide in blood give a valid and sensitive estimate of the average exposure during preceding months $(7,8)$.

The aim of this paper is to present the results of health surveys of the acrylamide-exposed tunnel workers, using $\mathrm{Hb}$ adducts as biomarkers of internal dose.

\section{Subjects and methods}

\section{Tunnel and the grouting technique}

The tunnel construction through the steep bedrock ridge had been severely delayed due to technical problems caused by the low quality of the rock, which was strongly cracked and had a very high water content. The standard grouting technique, using cement, did not prevent ground water from leaking into the tunnel in amounts twice as large as those allowed by the authorities. In the beginning of 1997, it was decided to use a chemical grouting agent in order to speed up the tunnel construction. A limited number of test groutings were performed from the end of March to the end of June 1997. From August 4 , immediately after summer vacations, to September 30, chemical grouting was performed on a large scale.

The grouting agent, Rhoca $\mathrm{Gil}^{\mathrm{TM}}$, was ready-mixed in the tunnel from two solutions and water. According to the declaration of content, solution 1 contained up to $1.5 \%$ acrylamide, about $37 \% \mathrm{~N}$-methylolacrylamide, and about $0.9 \%$ formaldehyde. Analyses performed on different batches of the product showed, however, that the acrylamide concentrations varied between $4.0 \%$ and $5.4 \%$, and the $\mathrm{N}$-methylolacrylamide concentrations ranged between $29 \%$ and 31\% (S Kinnunen, Skanska $\mathrm{AB}$, personal communication). Ten percent of solution 1 consisted, according to the content of declaration, of an accelerator that contained dimethyl adipate, dimethyl glutarate, dimethyl succinate, and triethanolamine. Solution 2 contained sodium silicate and sodium persulfate. The ready-mixed solution consisted of 3.75 parts water, 0.125 parts solution 1 , and 0.125 parts solution 2.

The grouting agent was pumped under pressure into 40 drill holes, each 9-m deep and radiating in 20-degree angles away from the tunnel front. The solution was pumped into mouthpieces of steel with rubber cuffs, which were placed in the drill holes. The workers could have been dermally exposed, sometimes to a substantial degree. Exposure also took place by inhalation, which was confirmed by two personal airborne samples taken in August 1997 and collected by the construction company's health service. The samples showed 0.27 and $0.34 \mathrm{mg} / \mathrm{m}^{3}$ for the sum of acrylamide and N-methylolacrylamide, respectively. The same day that the production closed down two new samples were drawn, showing that $50 \%$ of the sum consisted of acrylamide.

\section{Study group}

A week after the chemical grouting was stopped, it was agreed that all personnel that had been potentially exposed to the grouting agent should undergo a health examination. Representatives from the construction company made up a list of 242 subjects, including workers from subcontractors. Nineteen of the 242 did not participate, either claiming no exposure or that they had already left the company and were living far from the tunnel construction. Thirteen of these 19 workers answered a postal questionnaire, and none of them claimed any health problems related to contact with the grouting agent. The remaining 223 subjects underwent a full health examination, but 13 of them refused blood sampling. None of these 13 subjects claimed any health problems related to contact with the grouting agent. Thus the final study population comprised 210 workers, of which three were women. The group's median age was 44 (range 20-62) years.

\section{Venous blood sampling}

Venous blood samples were drawn into heparinized venoject tubes from 7 October to 6 November 1997 for the analysis of $\mathrm{Hb}$ adducts. For a verification of the presumed biological half-time of this biomarker, repeated blood samples were drawn for $\mathrm{Hb}$-adduct analysis from five of the exposed workers during the following 5month period. Blood samples were also drawn from 18 (11 men and 7 women) occupationally unexposed, non- 
smoking adult subjects. The tubes were cool stored before centrifugation. The erythrocyte fraction was separated, washed 3 times in physiological saline solution, and stored at $-70^{\circ} \mathrm{C}$ in plastic tubes pending analysis.

For the workers who were referred for a neurophysiological examination because of recently developed peripheral nervous symptoms, blood samples were drawn for the analysis of gamma-glutamyl transferase and carbohydrate-deficient transferrin in serum and fasting blood glucose according to routine techniques.

\section{Analysis of hemoglobin adducts}

The N-alkyl Edman method for the derivatization and specific detachment of adducted $\mathrm{N}$-terminal valines in hemoglobin with pentafluorophenyl isothiocyanate, and analysis by gas chromatography-tandem mass spectrometry, was used $(7,9)$. The method has earlier been adapted and applied to studies of humans occupationally exposed to acrylamide $(8,10)$. The adduct formed by acrylamide to $\mathrm{N}$-terminal valine in hemoglobin is $\mathrm{N}$-(2carbamoylethyl)valine (11). In vitro studies and experiments with rats have shown that $\mathrm{N}$-methyloacrylamide is measured as the same adduct as acrylamide (12). The adduct level from an absorbed amount of N-methyloacrylamide is one-third of the level of an equivalent amount of acrylamide. Standard compounds were kindly provided for the analysis by E Bergmark (8).

\section{Initial health examination and self-reported exposure categorization}

The full health examination, performed on 14 October to 17 November 1997, started with a self-administered questionnaire on medical history, smoking habits, alcohol consumption, job history, exposure to vibration, worktasks in tunnel construction, use of personal protection devices, and symptoms from the skin, mucous membranes and respiratory tract. Moreover, symptoms from the peripheral nervous system, such as numbness, tingling, or pain in hands, feet or legs were asked about. The subjects had to specify whether the symptoms had first appeared during the period of chemical grouting or whether they had had these symptoms earlier but that the symptoms had deteriorated during the grouting period.

A physician checked the questionnaire and asked complementary questions when needed. A physical examination was performed, including tests of peripheral nervous functions.

If the subject claimed recently developed or deteriorated peripheral nervous symptoms, with or without objective findings in the clinical examination, they were referred to a more-detailed neurophysiological examination. (See the Neurophysiological Examination section.) It should be borne in mind that, at the time of referral, no information on individual $\mathrm{Hb}$-adduct levels was available. Therefore, the referral was made on the basis of rather broad indicators, aiming primarily at a high sensitivity in the screening process.

The tunnel workers were classified with respect to self-reported exposure to the grouting agent. The "high" exposure category comprised the 103 subjects who had injected the chemical grouting agent with frequent skin exposure. The "low" exposure category comprised 18 subjects not obviously exposed to the grouting agent. The remaining 89 workers had been exposed to "some" extent.

\section{Neurophysiological examination}

A standardized neurophysiological examination was performed, comprising both motor (median and peroneal nerves) and sensory (median and sural nerves) neurography of the right extremities (13) and the measurement of sensory perception thresholds in the left foot (14). Reference ranges used for clinical purposes were employed $(13,14)$. Subjects with deviations from the reference values were categorized as having increased sensory perception thresholds, slight impairments of nerve function (affecting conduction velocity, distal latency or amplitude with or without increased perception thresholds), or signs of polyneuropathy (nerve conduction and perception thresholds generally affected to a degree that would support a clinical diagnosis of polyneuropathy). At the reexamination after 6 months, the course of events was classified as improved, unchanged, or deteriorated.

\section{Dermatological examination}

Because of a variety of persisting symptoms and signs from the skin, 30 of the workers were referred to an examination performed by specialists in occupational dermatology. Twenty-four of the subjects were tested for contact allergy with a standard series of 50 compounds and a specific series of 50 compounds with relevance for the occupational setting (grouting agents, acrylates, isocyanates, protective gloves, soaps, etc).

\section{Follow-up study}

The workers who, at the initial examination, had claimed recently developed or deteriorated peripheral nervous symptoms and had $\mathrm{Hb}$-adduct levels of at least 0.30 $\mathrm{nmol} / \mathrm{g}$ globin were followed up after 6 months with clinical ( $\mathrm{N}=29)$ and neurophysiological $(\mathrm{N}=26)$ reexaminations. Those with remaining symptoms were reinvestigated every 6 months up to 18 month after the cessation of exposure. 


\section{Statistical methods}

To investigate the differences in Hb-adduct levels between the workers with and without symptoms, the Mann-Whitney U-test was performed. Box plots were used to illustrate the difference in the Hb-adduct levels between the different exposure categories, and the Jonckheere-Terpstra test for trend was performed to evaluate these differences statistically. McNemar's test for correlated proportions was used for comparisons of proportions. Spearman's correlations were computed to assess the relation between continuous variables and $\mathrm{Hb}$ adduct levels, and Pearson's chi-square test was used to test for the prevalence of symptoms at different $\mathrm{Hb}$ adduct levels. The term "significant" refers to $\mathrm{P}<0.05$. The binomial distribution was used for calculating the 95\% confidence intervals (95\% CI) for proportions.

The probability of the different peripheral nerve symptoms was fit to a threshold model (equation 1) (15, 16), namely, a thresholded logistic regression model which is linear-quadratic in dose (measured by the $\mathrm{Hb}$ adduct level, $\mathrm{A})$, as follows:

$\log [\mathrm{P}(\mathrm{A}) / 1-\mathrm{P}(\mathrm{A})]=\alpha+\beta_{1}(\mathrm{~A}-\gamma)+\beta_{2}(\mathrm{~A}-\gamma)^{2}$. (equation 1)

$D-\gamma$ denotes the dose above threshold dose $\gamma$ (equation 2) and $\mathrm{P}(\mathrm{A})$ is the probability of the different symptoms as a function of $\mathrm{A}$, the $\mathrm{Hb}$-adduct level (ie, the dose), $a$ is the background frequency of the symptoms and $\beta_{1}, \beta_{2}$ are coefficients.

$$
\mathrm{D} \gamma=\begin{aligned}
& 0 \quad \text { if } \quad \mathrm{A}<\gamma \\
& \text { or }-\gamma \text { if } A \geq \gamma .
\end{aligned}
$$

(equation 2)

The 95\% confidence limits for the threshold parameter were estimated by the profile likelihood method. The model included a quadratic term to allow for the

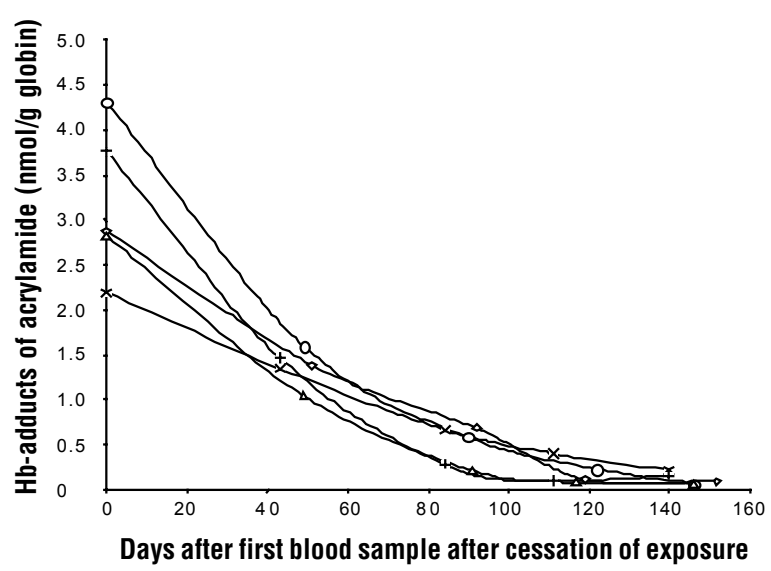

Figure 1. Decrease in hemoglobin-adduct levels of acrylamide for five highly exposed tunnel workers during 5 months after the cession of exposure to the grouting agent. First samples drawn $1-2$ weeks after the cessation of exposure. $(\mathrm{Hb}=$ hemoglobin) leveling off of the frequencies of many symptoms at high adduct levels. The upper confidence limit of a threshold estimate shows the adduct level below which a constant risk, equal to the background risk, cannot be significantly rejected; this limit has, therefore, the character of a no-observed adverse effect level (NOAEL).

\section{Results}

\section{Exposure to acrylamide and hemoglobin-adduct levels}

The $\mathrm{Hb}$-adduct levels of acrylamide of the 18 nonsmoking, unexposed reference subjects varied between 0.02 and $0.07 \mathrm{nmol} / \mathrm{g}$ globin. For 47 of the tunnel workers, the upper reference limit was not exceeded, while 74 of them had adduct levels over $0.30 \mathrm{nmol} / \mathrm{g}$ globin. A single extreme value of $17.7 \mathrm{nmol} / \mathrm{g}$ was observed, while the next highest value was 4.3 (table 1). Repeated sampling from five workers during a 5-month period after the end of exposure showed a decrease in the adduct levels that was compatible with the 120-day life span of human erythrocytes (figure 1).

On the group level, there was a significant $(\mathrm{P}<0.0001)$ and clear-cut association between the exposure categories on the basis of self-reports and the $\mathrm{Hb}$ adduct levels (figure 2). We did not find any high $\mathrm{Hb}$-adduct levels that could not be explained by the work history, although some workers in the high-exposure category had low Hb-adduct levels. None of the workers had used appropriate personal protection devices.

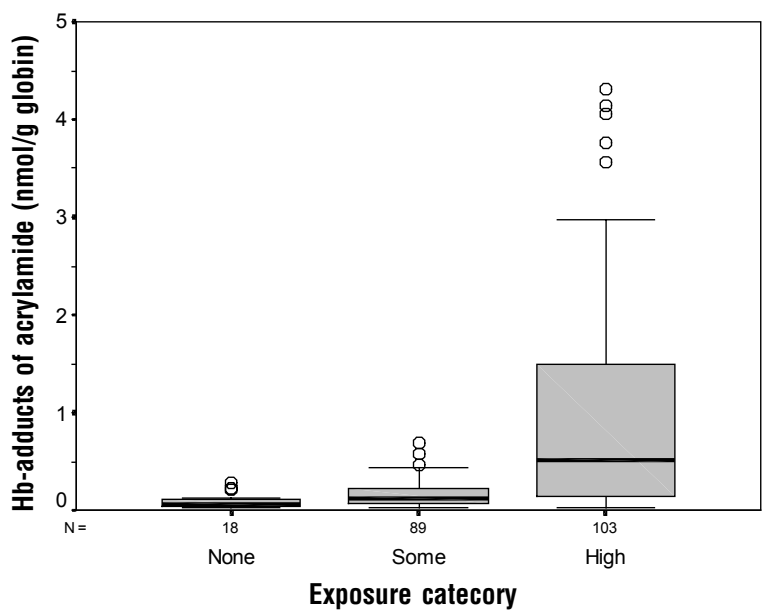

Figure 2. Hemoglobin-adduct levels of acrylamide with respect to selfreported exposure assessment. $(\mathrm{Hb}=$ hemoglobin, None = exposure only in the form of airborne contact or skin contact with contaminated leakage water, Some $=$ exposure in the form of infrequent skin contact with the chemical grouting agent, and high = frequent skin contact with the grouting agent) 


\section{Cross-sectional study of health effects}

There were obvious and significant dose-response associations between the $\mathrm{Hb}$-adduct levels and the prevalences of peripheral nervous symptoms, irritative symptoms of the skin, eyes and respiratory tract, and symptoms of general discomfort such as headache, nausea and dizziness (table 1). Thirty-nine percent of those with $\mathrm{Hb}$-adduct levels exceeding $1 \mathrm{nmol} / \mathrm{g}$ globin, experienced tingling or numbness in their hands or feet, and the symptom had developed during the few months that the workers had used the chemical grouting agent. As many as $87 \%$ of such highly exposed workers had experienced irritative symptoms of either the eyes or the respiratory tract, and $74 \%$ had had headache, nausea, or dizziness when using the chemical grouting agent. While the peripheral nervous symptoms started insidiously and remained even after the cessation of exposure, the respiratory tract symptoms and symptoms of general discomfort were of an acute character and disappeared after the end of the workday.

The upper confidence limit for the threshold dose (ie, a proxy for a NOAEL) was $0.51 \mathrm{nmol} / \mathrm{g}$ globin for numbness or tingling in the feet or legs, 1.28 for skin peeling of the hands, 1.86 for leg cramps, and above the highest observed adduct level for numbness or tingling in the hands.

The dermatological examination revealed occupationally induced hand eczema for 10 subjects, of which 2 had allergic contact dermatitis and 8 had irritant contact dermatitis. One of the 2 subjects with allergic con- tact dermatitis, who also had facial and neck eczema, showed contact allergy to two emulgators, cocamidopropyl betaine and polyethyleneglycol-3-cocamide, in the cleaning soap used at the workplace. The other worker showed contact allergy to sodium persulfate (used as an accelerator in the grouting solutions) and an allergic reaction to $\mathrm{N}$-methylolacrylamide, but no reaction to formaldehyde.

Twenty-nine of the fifty symptomatic workers referred for a neurophysiological examination due to recently developed or deteriorated peripheral nervous symptoms that, in some instances, were accompanied by objective findings in the clinical examination had adduct levels of at least $0.30 \mathrm{nmol} / \mathrm{g}$ globin. In previous studies, this adduct level was tentatively considered sufficient for an increased risk of impairment in peripheral nervous functions (17). Two of the 29 workers showed neurographic signs of polyneuropathy, 8 had slight impairments of nerve conduction or amplitude, 9 had increased sensory perception thresholds, and only 9 subjects were neurophysiologically "normal". Within the full group of 50 workers with peripheral nervous symptoms, there were no correlations between the serum levels of gamma-glutamyl transferase or carbohydrate-deficient transferrin or fasting blood glucose and $\mathrm{Hb}$-adduct levels (data not shown).

\section{Follow-up study of health effects}

Six months after first neurophysiological examination, the examination was repeated on 26 of the 29 workers

Table 1. Dose-response associations between hemoglobin $(\mathrm{Hb})$ adducts of acrylamide and work-related symptoms among 210 tunnel workers.

\begin{tabular}{|c|c|c|c|c|c|c|c|c|c|}
\hline \multirow[b]{3}{*}{ Symptoms } & \multicolumn{8}{|c|}{$\mathrm{Hb}$ adducts of acrylamide (nmol/g globin) } & \multirow[b]{3}{*}{ P-value ${ }^{a}$} \\
\hline & \multicolumn{2}{|c|}{$\begin{array}{l}<0.08 \\
(\mathrm{~N}=47)\end{array}$} & \multicolumn{2}{|c|}{$\begin{array}{c}0.08-0.29 \\
(\mathrm{~N}=89)\end{array}$} & \multicolumn{2}{|c|}{$\begin{array}{c}0.30-1.00 \\
(N=36)\end{array}$} & \multicolumn{2}{|c|}{$\begin{array}{l}>1.00 \\
(\mathrm{~N}=38)\end{array}$} & \\
\hline & N & $\%$ & N & $\%$ & N & $\%$ & $\mathrm{~N}$ & $\%$ & \\
\hline Numbness or tingling in hands & 6 & 13 & 12 & 13 & 11 & 31 & 11 & 29 & 0.04 \\
\hline Numbness or tingling in feet or legs & 2 & 4 & 10 & 11 & 9 & 25 & 14 & 37 & $<0.001$ \\
\hline Leg cramps & 3 & 6 & 6 & 7 & 2 & 6 & 10 & 26 & 0.003 \\
\hline Increased hand or foot sweating & 1 & 2 & 3 & 3 & 6 & 17 & 4 & 11 & 0.02 \\
\hline Skin peeling in hands & 3 & 6 & 2 & 2 & 3 & 8 & 9 & 24 & 0.001 \\
\hline Irritation of the eyes & 6 & 14 & 19 & 23 & 17 & 47 & 29 & 76 & $<0.001$ \\
\hline Irritation of the nose & 6 & 14 & 17 & 21 & 13 & 36 & 20 & 53 & $<0.001$ \\
\hline Irritation of the throat & 4 & 10 & 19 & 23 & 17 & 47 & 28 & 47 & $<0.001$ \\
\hline Coughing & 4 & 10 & 9 & 11 & 11 & 31 & 19 & 50 & $<0.001$ \\
\hline Dyspnea or wheezing & 1 & 2 & 7 & 9 & 6 & 17 & 9 & 24 & 0.02 \\
\hline Irritation of the skin & 6 & 14 & 15 & 18 & 11 & 31 & 15 & 39 & 0.02 \\
\hline Headache & 6 & 14 & 27 & 33 & 11 & 31 & 24 & 63 & $<0.001$ \\
\hline Nausea & 2 & 5 & 11 & 13 & 5 & 14 & 18 & 47 & $<0.001$ \\
\hline Dizziness & 3 & 7 & 11 & 13 & 11 & 31 & 9 & 24 & 0.02 \\
\hline
\end{tabular}

\footnotetext{
a Joncheere-Terpstra's test for trend.
} 
with symptoms and with adduct levels of at least 0.30 $\mathrm{nmol} / \mathrm{g}$ globin (table 2). Fifty-eight percent (95\% CI $37-77$ ) of the subjects showed improved test results, while the results showed deterioration for $4 \%$ only $(95 \%$ CI 0-20).

In a comprehensive assessment that took into consideration the $\mathrm{Hb}$-adduct level, medical history, clinical course and the results of the neurophysiological examinations at 0 and 6 months, 23 workers were regarded as having had impaired peripheral nervous functions due to occupational exposure to acrylamide. Six months after the exposure stopped, 12 of the 23 workers still had symptoms. The number of workers with symptoms was reduced to 3 after 12 months (table 3 ), and 2 of the 3 subjects had clinically improved in the 18-month examination, while the 3rd subject still had the same intensi-

Table 2. Result of the initial and 6-month follow-up neurophysiological examinations of the 26 tunnel workers with newly developed symptoms of the peripheral nervous system and hemoglobin-adduct levels of $>0.30 \mathrm{nmol} / \mathrm{g}$ globin.

\begin{tabular}{|c|c|c|c|}
\hline \multirow{2}{*}{$\begin{array}{l}\text { Result of the initial } \\
\text { neurophysiologycal } \\
\text { examination }\end{array}$} & \multicolumn{3}{|c|}{$\begin{array}{l}\text { Result of the neurophysiological } \\
\text { examination after } 6 \text { months }\end{array}$} \\
\hline & Improved a & Unchanged & Deteriorated \\
\hline Normal & $4^{b}$ & 5 & 0 \\
\hline $\begin{array}{l}\text { Increased sensory } \\
\text { perception thresholds }\end{array}$ & 5 & 2 & 0 \\
\hline $\begin{array}{l}\text { Slight impairments of nerve } \\
\text { conduction velocity or amplitude }\end{array}$ & 5 & 2 & 1 \\
\hline Signs of polyneuropathy & 1 & 1 & 0 \\
\hline \multicolumn{4}{|c|}{$\begin{array}{l}\text { a The proportion of the subjects with improved neurophysiology was } \\
\text { significantly higher than that of the subjects with deteriorated neuro- } \\
\text { physiology ( } \mathrm{P}=0.0005 \text {, McNemar's test for correlated proportions). } \\
\text { b The results of these four subjects were within the normal range in the } \\
\text { initial examination but showed higher nerve conduction velocities or } \\
\text { decreased sensory thresholds in the follow-up } 6 \text { months later. }\end{array}$} \\
\hline
\end{tabular}

Table 3. Clinical course and results of the neurophysiological examinations during an 18-month follow-up period for 23 tunnel workers considered to have a causal relationship between occupational exposure to acrylamide and impairment of peripheral nervous functions.

Results of neurophysiological examination

\begin{tabular}{lrrccc}
\cline { 4 - 5 } Time of examination & $N$ & Improved & Unchanged & Deteriorated & Not done \\
\hline After 6 months & 23 & & & & \\
$\quad$ Symptom-free & 11 & 8 & 3 & - & - \\
$\quad \begin{array}{l}\text { Remaining symp- } \\
\text { toms }\end{array}$ & 12 & 7 & 2 & 1 & 2 \\
After 12 months & 12 & & & & \\
$\quad$ Symptom-free & 9 & - & - & - & 9 \\
$\quad$ Remaining symp- & 3 & 1 & - & 2 & - \\
toms & & & & & \\
After 18 months & 3 & & & & 1 \\
$\quad$ Remaining symp- & 3 & 1 & - & 1 & 1 \\
toms & & & & & \\
\hline
\end{tabular}

ty of symptoms. The neurophysiological examinations were repeated at 12 and 18 months only when clinically indicated as necessary.

\section{Discussion}

The main result of this study was the clear-cut dose-response associations between $\mathrm{Hb}$-adducts of acrylamide and work-related peripheral nervous symptoms. These associations were supported by the results of neurophysiological examinations. Moreover, similar associations with $\mathrm{Hb}$-adduct levels were observed also for irritative symptoms from the respiratory tract, the eyes and the skin, and also for symptoms of general discomfort. The symptoms from the peripheral nervous system were generally mild and were, in almost all cases, reversible during an 18-month follow-up period after exposure cessation.

Since the 1950 s it has been reported that acrylamideexposed workers from, for example, the chemical industry have developed signs and symptoms of neurotoxicity (18). Peripheral neuropathy due to acrylamide affects both motor and sensory nerve fibers, predominantly in the distal parts of the limbs. Sensory symptoms usually consist of complaints of numbness of the feet and fingers. Evidence of excessive sweating affecting predominantly the distal parts of the limbs has been an almost universal finding in acrylamide neuropathy. Redness and exfoliation of the skin is usually present. In our study we found dose-response associations with $\mathrm{Hb}$ adducts of acrylamide for all these symptoms.

Case reports from both the United States (19) and Italy (20) have described peripheral neuropathy in tunnel workers due to acrylamide exposure from grouting agents, but the exposure levels were not quantified. In only one previous study was the exposure quantified using $\mathrm{Hb}$-adduct levels of acrylamide. Chinese workers who had been manufacturing acrylamide between 1 month and 11 years had $\mathrm{Hb}$-adduct levels between 0.3 and 33.8 (mean 9.5) nmol/g globin (10). Thus the average exposure level, corresponding to $9.5 \mathrm{nmol} / \mathrm{g}$, was considerably higher than in our study. A majority of the Chinese workers showed symptoms and signs of the peripheral nervous system, and a dose-response association between $\mathrm{Hb}$ adducts of acrylamide and a neurotoxic index constructed from neurophysiological findings and signs and symptoms of the peripheral nervous system was observed (21). Available data from the study on Chinese workers do not allow any firm threshold limit to be determined, but it could tentatively be assumed to correspond to an uptake that, in a few months of exposure, leads to an adduct level in the interval of $0.3-$ $1 \mathrm{nmol} / \mathrm{g}$ globin (17). In our study a proxy NOAEL value of $0.51 \mathrm{nmol} / \mathrm{g}$ globin was estimated for numbness 
or tingling in feet or legs, and this figure was in agreement with the estimates for the Chinese workers.

In a single previous case report, allergic contact dermatitis to acrylamide was found (22). In our study, only one subject developed contact allergy to N-methylolacrylamide, despite extensive and frequent dermal exposure of the workers to the grouting agent. This result supports the notion that these compounds are only weakly allergenic.

With respect to the validity of our study design, there was only a very low dropout rate from the examinations. We have full datasets for $87 \%$ of the potentially exposed group and limited information for another $10.5 \%$. A selection bias has therefore not affected our conclusions of the cross-sectional examination. Due to a lack of resources it was not possible to perform reexaminations of all the exposed workers at the time of the 6-month follow-up, and only those who had initially claimed recently developed or deteriorated peripheral nervous symptoms were examined. Thus it can be argued that the improvement in the symptoms and neurophysiological findings could have been due to a "regression to the mean" phenomenon. What speaks strongly against this possibility is, however, the very clear dose-response relationships between the $\mathrm{Hb}$-adduct levels and the peripheral nervous symptoms.

A Hb-adduct level of acrylamide was available for each subject, and this information reflected the integrated internal dose for the preceding months. Thus we were exceptionally well-off with respect to accurate and relevant dose measures, which minimized the exposure misclassification bias.

The employees were unaware of their Hb-adduct levels at the time of the initial health examination. Thus the very clear dose-response relationships observed between the $\mathrm{Hb}$-adduct levels and the symptoms speak against a misclassification of symptoms, due to, for example, anxiety or other psychological factors, being a bias of importance.

There are no indications that the observed associations between exposure to acrylamide and health effects are the result of confounding factors not dealt with. Neither age nor previous occupational exposure to vibration correlated with the Hb-adduct levels and they, therefore, did not confound the results. Moreover, within the group of 50 workers who initially claimed peripheral nervous symptoms, there were no associations between biochemical markers of excess alcohol consumption and $\mathrm{Hb}$-adduct levels. Therefore, alcohol abuse will not explain the observed dose-response associations. Handling the grouting agent also resulted in moderate exposure to formaldehyde. Two stationary measurements showed concentrations of 0.25 and $0.48 \mathrm{mg} / \mathrm{m}^{3}$, which can be compared with the Swedish occupational exposure limit of $0.60 \mathrm{mg} / \mathrm{m}^{3}$. It is therefore unlikely that the very high prevalences of irritative symptoms from the eyes and respiratory tract can be explained by airborne exposure to formaldehyde by more than a very limited extent.

Spencer \& Schaumberg (23) have concluded that, in most instances, acrylamide toxicity results from dermal absorption rather than from inhalation. The increment of the adduct level from inhaled acrylamides during 55 days of exposure (8-hour workdays) could be estimated from the following data. Based on the performed measurements, the average airborne levels of acrylamide and $\mathrm{N}$-methylolacrylamide were assumed to be $0.15 \mathrm{mg} / \mathrm{m}^{3}$ each. The rate constant for the elimination of acrylamide in vivo is 0.15 /hour $(6,10)$. Furthermore, the adduct level from an absorbed amount of N-methylolacrylamide is one-third the level from an equivalent uptake of acrylamide, as measured in rats (12). Under these assumptions the increment of the adduct level as a result of airborne exposure would be $0.25 \mathrm{nmol} / \mathrm{g}$ (17). This adduct level must be added to the background of about $0.04 \mathrm{nmol} / \mathrm{g}$, which would give about $0.30 \mathrm{nmol} / \mathrm{g}$ for a nonsmoker. Smoking 10 cigarettes/day would give 0.06 $\mathrm{nmol} / \mathrm{g}$ in addition. The fact that many of the tunnel workers had substantially higher adduct levels indicates that dermal exposure was probably of great importance to the uptake of acrylamides.

In conclusion, occupational exposure to a grouting agent containing acrylamide and $\mathrm{N}$-methylolacrylamide resulted in symptoms and signs of peripheral nervous dysfunction. The internal dose was quantified by means of $\mathrm{Hb}$ adducts. Clear-cut dose-response associations were seen between $\mathrm{Hb}$-adduct levels and symptoms. Thirty-nine percent of those with Hb-adduct levels exceeding $1 \mathrm{nmol} / \mathrm{g}$ globin experienced tingling or numbness in the hands or feet, and $87 \%$ of those in this exposure category had experienced irritative symptoms of either the eyes or the respiratory tract. After 18 months of follow-up only a few subjects still experienced peripheral nervous symptoms.

\section{Acknowledgments}

The authors wish to acknowledge the assistance of Anders Hemmingsson, Tore Larsson, Jan Stattin, and Ann Sturk, Skanska AB; and Berndt Wikström, Lars Wohlström, Elisabeth Nissen, and Christina Nillius, AB Previa; Anna Akantis, Åsa Amilon, Birgitta Björk, Katalin Lindholm, Anita Ohlsson, Helene Ottosson, Håkan Tinnerberg, Ulrika Wallin and Hans Welinder, Department of Occupational and Environmental Medicine, Lund University Hospital; and Bert Björkner, Marlene Isaksson, and Erik Zimerson, Department of Occupational and Environmental Epidemiology, Malmö 
University Hospital. The analyses of $\mathrm{Hb}$ adducts of acrylamide and the neurophysiological examinations were financed by Skanska AB, Sweden.

\section{References}

1. Miller MJ, Carter DE, Sipes IG. Pharmacokinetics of acrylamide in Fischer-344 rats. Toxicol Appl Pharmacol 1982;63:36-44.

2. Smith EA, Oehme FW. Acrylamide and polyacrylamide: a review of production, use, environmental fate and neurotoxicity. Rev Environ Health 1991;9:215-28.

3. International Agency for Research on Cancer (IARC). Some chemicals used in plastics and elastomers. Lyon: IARC, 1985:41-66. Monographs on the evaluation for carcinogenic risk of chemicals to humans, vol 39.

4. International Agency for Research on Cancer (IARC). Some industrial chemicals, volume 60. Lyon: IARC, 1994:43553. Monographs on the evaluation for carcinogenic risk of chemicals to humans, vol 60.

5. Dearfield KL, Abernathy CO, Ottey MS, Brantner JH, Hayes P. Acrylamide: its metabolism, developmental and reproductive effects, genotoxicity and carcinogenecity. Mutat Res 1988;195:45-77.

6. Calleman CJ. The metabolism and pharmacokinetics of acrylamide: implications for mechanisms of toxicity and human risk. Drug Metab Rev 1996;28:527-90.

7. Törnqvist M, Mowrer J, Jensen S, Ehrenberg L. Monitoring of environmental cancer initiators through hemoglobin adducts by the modified Edman method. Anal Biochem 1986;154:255-66.

8. Bergmark E. Hemoglobin adducts of acrylamide and acrylonitrile in laboratory workers, smokers, and nonsmokers. Chem Res Toxicol 1997;10:78-84.

9. Törnqvist, M. Epoxide adducts to N-terminal valine of hemoglobin. In: Everse J, Winslow RW, Vandegriff KD, editors. Methods in enzymology; vol 231. San Diego (CA), Academic Press, 1994:650-7.

10. Bergmark E, Calleman CJ, He F, Costa LG. Hemoglobin adducts in humans occupationally exposed to acrylamide. Toxicol Appl Pharmacol 1993;120:45—54.
11. Bergmark E. Hemoglobin dosimetry and comparative toxicity of acrylamide and its metabolite glycidamide [dissertation]. Stockholm: University of Stockholm, 1992.

12. Tareke E. Studies on background carcinogens [dissertation]. Stockholm: University of Stockholm, 1992.

13. Sundkvist G, Armstrong FM, Bradbury JE, Chaplin C, Ellis $\mathrm{SH}$, Owens DR, et al. Peripheral and autonomic nerve function in 259 diabetic patients with peripheral neuropathy treated with ponalrestat (an aldose reductase inhibitor) or placebo for 18 months. J Diabetes Complications 1992;6:123-30.

14. Sundkvist G, Lilja B, Nilsson H, Nilsson J-Å, Rosén I. Peripheral nerve dysfunction is reflected by loss of ankle reflexes but not by autonomic neuropathy in diabetic patients. Muscle Nerve 1997;20:740-3.

15. Granath F. Statistical problems in estimating a threshold in a dose-response model. In: Hothorn, L, editor. Statistical methods in toxicology. Lecture notes in medical informatics. Berlin: Springer-Verlag, 1991. Vol 43.

16. Granath F. In vivo dose, dose-response and cancer risk assessment [dissertation]. Stockholm: University of Stockholm, 1998.

17. Törnqvist M, Bergmark E, Ehrenberg L, Granath F. Riskbedömning av akrylamid [Risk assessment of acrylamide]. Solna (Sweden): Chemical Inspectorate, 1998. PM Nr 7/98. English abstract.

18. Le Quesne PM. Acrylamide. In: Spencer PS, Schaumburg $\mathrm{HH}$, editors. Experimental and clinical neurotoxicology. Baltimore/London: William \& Wilkins, 1980:309-25.

19. Keeson CM, Baird AW, Lawson DH. Acrylamide poisoning. Postgrad Med J 1977;53:16-7.

20. Mapp C, Mazzotta M, Bartolucci GB, Fabbri L. La neuropatia da acrilamide: prime osservazioni in Italia [Nervous system disease caused by acrylamide: First cases in Italy]. Med Lav 1977;68:1-12.

21. Calleman CJ, Wu Y, Tian G, Bergmark E, Zhang S, Deng H, et al. Relationships between biomarkers of exposure and neurological effects in a group of workers exposed to acrylamide. Toxicol Appl Pharmacol 1994;126:361—71.

22. Lambert J, Matthieu L, Dockx P. Contact dermatitis from acrylamide. Contact Dermatitis 1988;19:65.

23. Spencer PS, Schaumburg HH. A review of acrylamide neurotoxicity, I: properties, uses and human exposure. Can J Neurol Sci 1974;1:143-150.

Received for publication: 6 November 2000 